\title{
Nowe wytyczne dotyczące leczenia bólu neuropatycznego
}

\section{New guidelines for the treatment of neuropathic pain}

\author{
Adam Stępień, Teofan M. Domżał
}

Klinika Neurologii, Woiskowy Instyłut Medyczny w Warszawie

Neurologia i Neurochirurgia Polska 2010; 44, 5: 437-442

Od kilkunastu lat walka z bólem jest jednym z głównych priorytetów w krajach wysoko rozwiniętych. W odpowiedzi na apele lekarzy i towarzystw naukowych ból uznany został za zbędne cierpienie chorego, z którym należy walczyć wszystkimi dostępnymi metodami, gdyż, jak stwierdzono, każdy człowiek ma prawo do życia bez bólu. Ból uznano także za jeden z pięciu - obok tętna, temperatury, świadomości i liczby oddechów parametrów życia. Również i w naszym kraju pojawiają się szpitale i ośrodki medyczne, w których walka z bólem jest priorytetem w opiece nad chorym, m.in. skutecznie rozwija się akcja „Szpital wolny od bólu”. Równocześnie w wielu krajach podjęto zakrojone na szeroką skalę badania pozwalające na dokładniejsze poznanie skali występowania różnych zespołów bólowych, kosztów bezpośrednich i pośrednich ponoszonych przez społeczeństwa. Dało to podstawy do opracowania wytycznych i zaleceń opartych na danych naukowych, zebranych zgodnie z zasadami medycyny opartej na dowodach naukowych EBM (evidence-based medicine). Uzyskane wyniki potwierdziły, że jednym z często stwierdzanych rodzajów bólu jest ból neuropatyczny, którego klasycznym przykładem jest bolesna neuropatia cukrzycowa. Ma on wiele cech wyróżniających od innych zespołów bólowych, zarówno patogenetycznych, jak i klinicznych, przez co został on wyodrębniony i opracowano oddzielne zalecenia terapeutyczne.

Szacuje się, że z powodu bólu neuropatycznego cierpi ok. 7-8\% populacji w Europie [1]. Ból ten powstaje w następstwie uszkodzenia układu nerwowego, pierw- szego neuronu czuciowego. Znane są jego różne postacie kliniczne i wszystkie cechują się znacznym stopniem upośledzenia sprawności chorego. Cechy kliniczne bólu neuropatycznego to ostry, palący lub kłujący charakter, przebiegający wzdłuż określonego nerwu obwodowego, zaburzenia czucia, alodynia, parestezje i dyzestezje oraz słaba odpowiedź na standardowe leki przeciwbólowe bądź jej brak. Badania dowodzą również, że chorzy z tym rodzajem bólu mają istotnie obniżoną jakość życia. Ten rodzaj bólu najczęściej powstaje w przebiegu cukrzycy (diabetic painful neuropathy - DPN), infekcji wirusem półpaśca, a niekiedy, jak w przypadku neuralgii trójdzielnej, jego przyczyna pozostaje nieznana.

Skuteczność klasycznych leków przeciwbólowych w leczeniu bólu neuropatycznego, w tym najpowszechniej stosowanych niesteroidowych leków przeciwzapalnych (NLPZ), jest stosunkowo niewielka. Z badań przeprowadzonych w Stanach Zjednoczonych wynika, że aż $52,9 \%$ chorych otrzymuje $z$ tego powodu opioidy, $39,7 \%$ NLPZ, 21,1\% benzodiazepiny, 14,3\% selektywne inhibitory wychwytu zwrotnego serotoniny (SSRI), 11,1\% leki przeciwpadaczkowe (LPP), a 11,3\% trójpierścieniowe leki przeciwdepresyjne (TLPD). W krajach europejskich odsetek chorych otrzymujących leki z ww. grup nie różni się istotnie, poza mniejszą liczbą chorych leczonych opioidami. Poza zwalczaniem bólu istotnym problemem medycznym jest walka $\mathrm{z}$ objawami towarzyszaccymi, narastającymi wraz z czasem trwania bólu. U ponad połowy chorych stwierdza się zaburzenia snu, apatię, trudności w koncentracji uwa-

Adres do korespondencii: prof. dr hab. med. Adam Stępień, prof. dr hab. med. dr h.c. Teofan M. Domżał, Klinika Neurologii WIM, ul. Szaserów 128, 04-141 Warszawa, tel. +48 2268164 46, e-mail: astepien@wim.mil.pl

Pracę otrzymano: 21.06.2010; przyięto do druku: 19.07.2010 
gi, lęk, depresję oraz inne objawy upośledzające prawidłowe funkcjonowanie społeczne [2]. Współcześnie, co podkreślane jest w nowych zaleceniach, leczenie bólu neuropatycznego stało się problemem interdyscyplinarnym, z uwzględnieniem farmakoterapii, rehabilitacji oraz terapii behawioralnej i innych technik wspomagających. $\mathrm{W}$ piśmiennictwie tematu badania porównawcze oceniające poszczególne metody nie ujawniają wyższości jednej z nich nad pozostałymi. Ponadto nie wiadomo, która z metod leczenia dodana do farmakoterapii przynosi choremu najwięcej korzyści. Mechanizm korzystnego działania wielu zalecanych preparatów nadal nie został poznany. Często stosuje się kombinacje różnych leków o odmiennych mechanizmach działania. Ich dobór zależy w dużej mierze od wiedzy i doświadczenia leczącego. Stąd konieczność zmiany panujących poglądów odnośnie do terapii i opracowania jednolitych zasad jej prowadzenia.

Pierwsze wytyczne dotyczące leczenia bólu neuropatycznego zostały opracowane przez ekspertów z IASP w 2005 r. [3]. Ich znacznym mankamentem był brak wystarczających danych z badań klasy A. Zalecenia te oparto na stosunkowo niewielkiej liczbie badań klinicznych przeprowadzonych zgodnie z zasadami EBM oraz kryteriach wyznaczanych przez wartości wskaźników NNT (number needed to treat - liczba badanych, którą w określonym czasie należy poddać interwencji, aby uzyskać pożądany efekt zdrowotny lub uniknąć jednego negatywnego punktu końcowego u jednego badanego) i NNH number needed to harm - liczba leczonych, u których dana interwencja doprowadza do wystąpienia jednego dodatkowego niekorzystnego punktu końcowego w określonym czasie; obliczana jako odwrotność bezwzględnego zwiększenia ryzyka). Podkreślono w nich, że najniższy NNT w leczeniu bólu neuropatycznego cechuje TLPD.

Rok później (2006) ukazały się zalecenia ekspertów amerykańskich z Mayo Clinic [4]. Równocześnie opublikowano także wytyczne grupy ekspertów EFNS, w których oprócz skuteczności działania leków uwzględniono dane dotyczące jakości życia, wpływu leczenia na sen i oddziaływania chorób wspólistniejących [5]. Wytyczne te obejmowały bolesną polineuropatię obwodową (w tym cukrzycową), neuralgię po przebytym półpaścu, nerwoból trójdzielny oraz ból ośrodkowy. W przypadku bolesnej polineuropatii za leki pierwszego rzutu uznano gabapentynę, pregabalinę, lignokainę stosowaną miejscowo oraz TLPD. Lekami drugiego rzutu są natomiast lamotrygina, opioidy i selektywne inhibitory wychwytu zwrotnego serotoniny i noradrenaliny (SNRI) oraz tramadol.
Według wytycznych amerykańskich pierwszorzędowym celem leczenia powinno być zniesienie lub jak największe złagodzenie bólu. Autorzy tego opracowania wskazywali, że choremu należy uświadomić, iż pełne zniesienie bólu może okazać się niemożliwe. Nie zwalnia to jednak lekarza z podejmowania prób maksymalizacji efektu przeciwbólowego leków. Drugorzędowym celem leczenia jest natomiast poprawa funkcjonowania i jakości życia pacjenta.

Ze względu na siłę dowodów uzyskanych z badań $z$ randomizacją zalecane leki podzielono na pierwszego i drugiego rzutu oraz pozostałe. Osobną kategorię stanowią preparaty stosowane miejscowo. Do leków pierwszego rzutu zaliczono duloksetynę, oksykodon CR, pregabalinę i TLPD. Za leki drugiego rzutu uznano karbamazepinę, gabapentynę, lamotryginę, tramadol oraz wenlafaksynę ER. Wśród pozostałych leków wymieniono bupropion, citalopram, metadon, paroksetynę, fenytoinę i topiramat.

Od tego czasu pojawiały się liczne nowe dane naukowe. Okresowo w piśmiennictwie dokonywano także przeglądu i nowelizacji tych zaleceń [6]. Tak też stało się obecnie. W tym roku zarówno specjaliści z EFNS, jak i grupa ekspertów Kliniki Mayo opublikowali uaktualnione wytyczne. Zmienione zostały także zalecenia ekspertów kanadyjskich [7]. Publikacje te zbiegły się w czasie z pracami krajowej grupy osób skupionych wokół Komisji Patofizjologii i Terapii Bólu Komitetu Nauk Neurologicznych Polskiej Akademii Nauk. Na ostatnim spotkaniu, w końcu listopada 2009 r. w Krakowie, podjęto bowiem decyzję o konieczności aktualizacji także naszych zaleceń, które zostały opracowane i opublikowane w czasopiśmie „Ból” w 2004 r. [8].

Mając jednak na uwadze postępującą światową unifikację, stoimy na stanowisku, że współcześnie nie ma już konieczności wyodrębniania nowych zaleceń krajowych, gdyż nie będą one odmienne od aktualnych opracowań międzynarodowych. Wszystkie opierają się na wynikach i analizach badań wieloośrodkowych opublikowanych w piśmiennictwie światowym, co nie znaczy, że każde z nich może być modyfikowane przez narodowe towarzystwa naukowe oraz zdobywane $z$ czasem doświadczenie kliniczne uwzględniające specyfikę krajowych rynków farmaceutycznych. Uwagi te można jednak zawrzeć w komentarzu do opracowanych zaleceń międzynarodowych.

$Z$ wielu aktualnych badań $\mathrm{z}$ randomizacją i z grupa kontrolną otrzymującą placebo oceniających skuteczność rozmaitych leków wynika, że efekty terapii wciąż nie są satysfakcjonujące. Blisko połowa chorych nie 
odczuwa poprawy po żadnym z zalecanych leków, a jedynie u połowy chorych udaje się zredukować jego natężenie o połowę [9]. Badania z grupami kontrolnymi przeprowadzone były u chorych podzielonych według przyczyn wywołujących ból. Przewaga dotyczyła chorych na DPN i neuralgię popółpaścową. Dowodzą one, że jedynie kilka leków ma rzeczywistą skuteczność terapeutyczną, tzn. NNT dla tych leków jest $<5,0$ $[10]$. Biorąc pod uwagę doświadczenie kliniczne zdobyte w leczeniu DPN, z pewnym prawdopodobieństwem można ekstrapolować wyniki tych badań także na inne postacie bólu neuropatycznego.

Zarówno w nowo opublikowanych zaleceniach EFNS, jak i grupy ekspertów Kliniki Mayo oraz zaleceniach kanadyjskich kilka kwestii pozostaje do indywidualnej decyzji lekarza. Należy do nich dobór leku pierwszego rzutu, co z kolei pociąga za sobą pytanie, jakie zastosować kryteria. Czy jest nim czas trwania bólu, czy też jego charakter? Oddzielnym zagadnieniem jest bezpieczeństwo i tolerancja ordynowanych leków oraz rzeczywisty koszt leczenia. Stosowane są one bowiem przewlekle, wiele miesięcy, a nawet lat. Decyzja taka powinna być podjęta po wspólnej rozmowie i ustaleniach lekarza i pacjenta. W farmakoterapii bólu neuropatycznego szczególnie skuteczne okazały się leki przeciwpadaczkowe i przeciwdepresyjne, przy czym klasyczne (TLPD) są skuteczniejsze niż leki z innych grup, w tym SSRI. Te ostatnie w zasadzie nie wykazują skuteczności istotnie statystycznie wyższej niż placebo. Wyjątkiem okazały się jedynie wenlafaksyna i ostatnio duloksetyna.

Inne leki, w tym opioidy, leki miejscowo znieczulające i kortykosteroidy, znajdują zastosowanie jedynie w ograniczonym zakresie, najczęściej okresowo. W Polsce leki uznane za szczególnie skuteczne nie są refundowane, przez co koszty leczenia są nie do zaakceptowania przez wielu chorych. Powoduje to, że stosowane leki mają ograniczoną skuteczność lub - co gorsza chorzy nie są leczeni wcale.

Skuteczność TLPD jest poparta wieloletnim doświadczeniem klinicznym. Trzeba jednak zauważyć, że w literaturze na ten temat nie ma badań wieloośrodkowych $\mathrm{z}$ randomizacją i z zastosowaniem placebo, oceniających ich skuteczność w leczeniu neuropatii cukrzycowej [11]. Dostępne są natomiast badania jednoośrodkowe, w których zwłaszcza amitryptylina uznawana jest za lek najskuteczniejszy. $Z$ innych leków przeciwdepresyjnych badania kliniczne wskazują na wenlafaksynę jako preparat o korzystnym wpływie na zmniejszenie odczuć bólowych [12]. Nowszym lekiem jest duloksetyna, inhibitor wychwytu zwrotnego serotoniny i noradrenaliny.
Blokując ich wychwyt zwrotny, zwiększa się ilość neuroprzekaźników w przestrzeni pomiędzy neuronami [13]. Lek zatwierdzony został przez FDA do obrotu i leczenia bólu neuropatycznego w 2004 r. Dotychczas przeprowadzono 3 badania kliniczne $\mathrm{z}$ randomizacją dotyczące porównania duloksetyny z placebo w leczeniu bólu neuropatycznego w przebiegu neuropatii cukrzycowej wykazujące jej wyższość nad placebo [14-16].

Inną grupą preparatów stosowanych od wielu lat są leki przeciwpadaczkowe, które wielu autorów uznaje za leki pierwszego rzutu. Współczynnik NNT dla związków pierwszej generacji wynosi średnio 2,7 (od 2,2 do $3,8)$ [17]. W tej grupie znajdują się leki o odmiennych mechanizmach działania. Jedynie nieliczne z nich były poddane nowoczesnym badaniom skuteczności klinicznej. Ponadto takie związki, jak fenytoina, kwas walproinowy, lewetyracetam i zonisamid, nie były oceniane zgodnie $z$ zasadami EBM lub oceny skuteczności nie są miarodajne. $Z$ tego powodu nie są one zalecane w leczeniu bólu neuropatycznego i nie znalazły się w opublikowanych rekomendacjach.

Ugruntowaną i wysoką pozycję w leczeniu bólu neuropatycznego mają natomiast pregabalina i gabapentyna, które są lekami obecnie najczęściej stosowanymi na świecie. Działają one na podjednostkę $\alpha-2-\delta$ drobiny białka $G$ napięciowego kanału wapniowego, co powoduje hiperpolaryzację błony komórkowej [18]. Dysponujemy licznymi badaniami z randomizacją i z zastosowaniem placebo wykazującymi korzystne działanie obydwu leków w różnych postaciach bólu neuropatycznego, w tym w przebiegu cukrzycy, w neuralgiach, bólu fantomowym, pourazowym i zespole Guillaina-Barrégo oraz w bólu ośrodkowym [19-23].

Wyniki badań klinicznych z randomizacją porównujących główne leki względem placebo dowiodły, że zarówno pregabalina (w dawce 300 i $600 \mathrm{mg}$ dziennie), gabapentyna (w dawce 900-3600 mg dziennie), jak i duloksetyna (w dawce $60 \mathrm{mg}$ raz dziennie i $60 \mathrm{mg}$ dwa razy dziennie) są lekami o udowodnionej skuteczności w leczeniu chorych $\mathrm{z}$ bólem w przebiegu neuropatii cukrzycowej [24].

Skuteczność gabapentyny porównywana była z TLPD. W badaniu oceniającym gabapentynę w dawce dziennej $1800 \mathrm{mg}$ w stosunku do amitryptyliny w dawce $75 \mathrm{mg}$ w leczeniu DPN dowiedziono, że obydwa leki cechuje zbliżona skuteczność i częstość występowania objawów ubocznych [25]. W innym badaniu porównawczym skuteczność gabapentyny w tym rodzaju bólu neuropatycznego była większa niż wenlafaksyny [26]. Pregabalina okazała się wysoce skutecz- 
na także w neuralgii po półpaścu. Poza zniesieniem doznań bólowych lek poprawiał sen i nastrój chorych $[27,28]$. W jednym z badań odsetek chorych, u których odnotowywano redukcję bólu o ponad 30\% i 50\%, ponad dwukrotnie przekraczał efekt placebo $-68 \%$ wobec $25 \%$ i $50 \%$ wobec $20 \%$; $p=0,001$ [29]. Wskaźnik NNT dla tego leku przy dawce $600 \mathrm{mg}$ wynosi 4,2 $(3,4-5,4)$, a NNH wynosi 11,7 (8,3-19,9).

Trzeba jednak zaznaczyć, że pregabalina w małej dawce (150 mg dziennie) nie przynosi korzyści w terapii bolesnej neuropatii cukrzycowej. Duloksetyna poza działaniem przeciwbólowym poprawia jakość życia chorych, co wynika $z$ działania przeciwdepresyjnego leku [30-33]. Wyniki dotychczasowych badań nie ujawniają istotnych statystycznie różnic, zarówno w od niesieniu do skuteczności i profilu bezpieczeństwa pomiędzy duloksetyną a pregabaliną, jak i pomiędzy duloksetyną a gabapentyną. Do najczęściej występujących działań niepożądanych związanych z leczeniem wymienionymi lekami należą zawroty głowy oraz senność. Duloksetyna stanowi obecnie ciekawą alternatywę

Tabela 1. Zestawienie leków rekomendowanych w 2010 r. przez European Federation of Neurological Societies w leczeniu bólu neuropatycznego w przebiegu neuropatii cukrzycowej

Table 1. Comparison of the drugs recommended by EFNS in 2010 in the treatment of neuropathic pain in diabetic polyneuropathy

\begin{tabular}{|ll|}
\hline Leki pierwszego rzutu & Leki drugiego i trzeciego rzutu \\
\hline duloksetyna & opioidy \\
\hline gabapentyna & $\begin{array}{l}\text { selektywne inhibitory wychwytu } \\
\text { zwrotnego serotoniny } \\
\text { i noradrenaliny }\end{array}$ \\
\hline pregabalina & tramadol \\
\hline $\begin{array}{l}\text { trójpierścieniowe leki } \\
\text { przeciwdepresyjne }\end{array}$ & lamotrygina \\
\hline wenlafaksyna ER & \\
\hline
\end{tabular}

Tabela 2. Zestawienie leków rekomendowanych w 2010 r. przez European Federation of Neurological Societies w leczeniu bólu neuropatycznego w przebiegu neuralgii po półpaśsu

Table 2. Comparison of the drugs recommended by EFNS in 2010 in the treatment of neuropathic pain in postherpetic neuralgia

\begin{tabular}{|ll|}
\hline Leki pierwszego rzutu & Leki drugiego i trzeciego rzutu \\
\hline gabapentyna & kapsaicyna \\
\hline pregabalina & opioidy \\
\hline $\begin{array}{l}\text { trójpierścieniowe leki } \\
\text { przeciwdepresyjne }\end{array}$ & tramadol \\
\hline $\begin{array}{l}\text { lidokaina - plastry } \\
\text { (na małym obszarze alodynii) }\end{array}$ \\
\hline
\end{tabular}

dla leków przeciwpadaczkowych nowej generacji. Wszystkie omawiane preparaty zostały zarejestrowane do leczenia bólu w neuropatii cukrzycowej.

Karbamazepina jest najstarszym $z$ leków stosowanych w leczeniu bólu neuropatycznego. Dowody dotyczące jej skuteczności nie są poparte dostatecznymi badaniami klinicznymi przeprowadzonymi zgodnie z wymogami EBM. Brakuje także badań porównawczych z lekami nowej generacji, w tym zwłaszcza z pregabaliną i duloksetyną. Jednak, jak potwierdza praktyka kliniczna, jest to preparat skuteczny i ma wysoką pozycję w arsenale leków stosowanych w bolesnych neuropatiach. Dotychczas nie dysponujemy także badaniami bezpośrednio porównującymi duloksetynę z pregabaliną lub gabapentyną w terapii bólu neuropatycznego.

Aktualnie opublikowane rekomendacje EFNS oparte zostały wyłacznie na badaniach z grupa kontrolna otrzymującą placebo i obejmują różne postacie bólu neuropatycznego. Ocenie poddano zarówno stopień ustąpienia bólu, jak i oddziaływanie na jakość życia pacjentów, wpływ na sen oraz częstość występowania objawów ubocznych. Do leków pierwszoplanowych zaliczono: pregabalinę, duloksetynę, gabapentynę, TLPD oraz wenlafaksynę ER (tab. 1.).

Leki te mają zasadniczo podobną siłę działania i skuteczność w zwalczaniu przewlekłego bólu neuropatycznego w przebiegu neuropatii cukrzycowej. Analiza danych nie uwzględniła bólu powstałego w następstwie neuralgii trójdzielnej, przewlekłej radikulopatii i neuropatii w przebiegu HIV. Leki te mają poziom rekomendacji A. W zaleceniach wskazuje się także, że stosowanie terapii łączonej może przynieść choremu dodatkowe korzyści. Dotyczy to zwłaszcza połączeń TLPD z gabapentyną oraz gabapentyny z opioidami (poziom zaleceń A).

$\mathrm{W}$ neuralgii powstałej po przebytej infekcji wirusem półpaśca jako leki pierwszego rzutu zalecane są pregabalina, gabapentyna, TLPD oraz lidokaina w plastrach. W grupie tej nie ma duloksetyny, gdyż do dzisiaj nie dysponujemy przekonującymi badaniami $\mathrm{w}$ tym zakresie. W grupie leków drugiego rzutu znalazły się kapsaicyna, opioidy, tramadol i kwas walproinowy. Lidokaina w plastrach jest szczególnie wskazana u osób starszych, cechuje się bowiem wysoką skutecznością i dobrą tolerancją (klasa zaleceń IV) (tab. 2.).

W leczeniu neuralgii trójdzielnej w grupie leków o udowodnionej skuteczności znalazły się jedynie dwa preparaty - karbamazepina i okskarbamazepina. W przypadku braku skuteczności tych leków zalecane jest leczenie chirurgiczne (tab. 3.). 
Natomiast w leczeniu bólu ośrodkowego do leków pierwszego rzutu zaliczono amitryptylinę oraz inne leki z grupy TLPD, a także pregabalinę i gabapentynę. $\mathrm{W}$ grupie leków drugiego rzutu wymienia się lamotryginę, opioidy, tramadol oraz kanabinoidy z obwarowaniem, że można je stosować w leczeniu bólu u chorych na stwardnienie rozsiane (tab. 4.).

Leki zalecane w innych postaciach bólu neuropatycznego, w tym w przebiegu infekcji HIV, bólu pourazowym, przewlekłej radikulopatii, bólu nowotworowym i innych rzadko spotykanych zespołach bólowych, zestawiono w tab. 5. Podziału dokonano w zależności od prawdopodobieństwa stopnia skuteczności opartego na dostępnych badaniach i doniesieniach w piśmiennictwie, w tym na obserwacjach jednoośrodkowych bez stosowania placebo jako punktu odniesienia.

$\mathrm{Z}$ praktyki klinicznej wiemy, że opioidy w terapii bólu neuropatycznego stosowane są rzadziej, przede wszystkim z powodu mniejszej skuteczności, od leków przeciwdepresyjnych i przeciwpadaczkowych. Zalecane są głównie u chorych ze znacznym nasileniem bólu i opornością na preparaty wcześniej stosowane. Ich efektywność została udowodniona w badaniach z grupą kontrolną otrzymującą placebo i nie wiąże się z uzależnieniem od nich. Tym niemniej przez część autorów nie są zalecane $[34,35]$. Skuteczna jest zarówno morfina, jak i fentanyl oraz oksykodon [36]. Obecnie polecany jest zwłaszcza fentanyl $\mathrm{w}$ formie plastrów transdermalnych o powolnym uwalnianiu leku. W leczeniu uzupełniającym zaleca się fizykoterapię i psychoterapię.
Uaktualnione zalecenia są godne rozpowszechnienia z kilku powodów, z których dwa wydają się nam najistotniejsze. Po pierwsze - jednoznacznie wskazują, które leki mają udowodnioną skuteczność kliniczną i powinny być stosowane, po drugie - dowodzą, że wiele preparatów, które są dość powszechnie zapisywane, nie ma de facto przypisywanej im skuteczności i nie należy ich stosować. Wiedza na ten temat poprawi skuteczność leczenia chorych oraz obniży jego koszty, zarówno indywidualne, jak i społeczne. Wytyczne te stanowią także

Tabela 3. Zestawienie leków rekomendowanych w 2010 r. przez European Federation of Neurological Societies w leczeniu bólu neuropatycznego w przebiegu neuralgii tróidzielnej

Table 3. Comparison of the drugs recommended by EFNS in 2010 in the treatment of neuropathic pain in trigeminal neuralgia

\begin{tabular}{|ll|}
\hline Leki pierwszego rzutu & Leki drugiego i trzeciego rzutu \\
\hline okskarbazepina & leczenie chirurgiczne \\
\hline karbamazepina & \\
\hline
\end{tabular}

Tabela 4. Zestawienie leków rekomendowanych w 2010 r. przez European Federation of Neurological Societies w leczeniu bólu ośrodkowego

Table 4. Comparison of the drugs recommended by EFNS in 2010 in the treatment of central pain

\begin{tabular}{|ll|}
\hline Leki pierwszego rzutu & Leki drugiego i trzeciego rzutu \\
\hline amitryptylina & kanabinoidy (stwardnienie rozsiane) \\
\hline gabapentyna & lamotrygina \\
\hline pregabalina & opioidy \\
\hline $\begin{array}{l}\text { trójpierścieniowe } \\
\text { leki przeciwdepresyjne }\end{array}$ & tramadol \\
\hline
\end{tabular}

Tabela 5. Zestawienie leków rekomendowanych w $2010 \mathrm{r}$. przez European Federation of Neurological Societies w leczeniu rzadkich postaci bólu neuropatycznego Table 5. Comparison of the drugs recommended by EFNS in 2010 in the treatment of rare cases of neuropathic pain

\begin{tabular}{|c|c|c|c|}
\hline Przyczyna bólu neuropatycznego & $\begin{array}{l}\text { Poziom A } \\
\text { („,ustalona" skuteczność) }\end{array}$ & $\begin{array}{l}\text { Poziom B } \\
\text { („prawdopodobna” } \\
\text { skuteczność) }\end{array}$ & $\begin{array}{l}\text { Poziom A/B } \\
\text { (mała skuteczność, } \\
\text { rozbieżne wyniki) }\end{array}$ \\
\hline neuropatia wywołana zakażeniem HIV & $\begin{array}{l}\text { kapsaicyna, } 8 \% \text { plastry } \\
\text { kanabinoidy }\end{array}$ & lamotrygina & \\
\hline BN pourazowy, po leczeniu chrurgicznym & & $\begin{array}{l}\text { amitryptylina } \\
\text { toksyna botulinowa A }\end{array}$ & \\
\hline przewlekły ból korzeniowy & & & pregabalina \\
\hline BN w chorobach nowotworowych & gabapentyna & $\begin{array}{l}\text { amitryptylina } \\
\text { tramadol }\end{array}$ & \\
\hline ból fantomowy & $\begin{array}{l}\text { morfina } \\
\text { tramadol }\end{array}$ & & \\
\hline wieloetiologiczny/złożony BN & $\begin{array}{l}\text { bupropion } \\
\text { kanabinoidy } \\
\text { leworfanol }\end{array}$ & $\begin{array}{l}\text { metadon } \\
\text { trójpierścieniowe leki } \\
\text { przeciwdepresyjne } \\
\text { (nortryptylina, klomipramina) }\end{array}$ & \\
\hline
\end{tabular}

$B N-$ ból neuropatyczny 
ważny oręż w walce o uzyskanie zrozumienia wśród osób odpowiedzialnych za politykę zdrowotną, chodzi bowiem o to, aby leki najskuteczniejsze były dostępne najbardziej potrzebującym, często niezamożnym chorym.

\section{Oświadczenie}

Autorzy zgłaszają brak konfliktu interesów.

\section{Piśmiennictwo}

1. Bouhassira D., Lanteri-Minet M., Attal N. i wsp. Prevalence of chronic pain with neuropathic characteristics in the general population. Pain 2008; 136: 380-387.

2. Meyer-Rosberg K., Kvarnstrom A., Kinnman E. i wsp. Peripheral neuropathic pain - a multidimensional burden for patients. Eur J Pain 2001; 5: 379-389.

3. Finnerup N.B., Otto M., McQuay H.J. i wsp. Algorithm for neuropathic pain treatment: an evidence based proposal. Pain 2005; 118: 289-305.

4. Consensus guidelines: treatment planning and options. Mayo Clinic Proc 2006; 81 (supl. 4): 12-25.

5. Attal N., Cruccu G., Haanpaa M. i wsp.; EFNS Task Force. EFNS guidelines on pharmacological treatment of neuropathic pain. Eur J Neurol 2006; 13: 1153-1169.

6. Dworkin R.H., O’Connor A.B., Backonja M. i wsp. Phar macologic management of neuropathic pain: evidence-based recommendations. Pain 2007; 132: 237-251.

7. Canadian Diabetes Association. Clinical practice guidelines for the prevention and management of diabetes in Canada. Can J Diabetes 2008; 32 (supl. A): 1-15.

8. Stępień A. Leczenie bólu neuropatycznego - propozycje terapeutyczne oparte na kontrolowanych badaniach klinicznych. Ból 2006; 7: 17-23.

9. Dworkin R.H., Backonja M., Rowbotham M.C. i wsp. Advances in neuropathic pain: diagnosis, mechanisms, and treatment recommendations. Arch Neurol 2003; 60: 1524-1534.

10. Hempenstall K., Nurmikko T.J., Johnson R.W. i wsp. Analgesic therapy in postherpetic neuralgia: a quantitative systematic review. Public Library Sci Med 2005; 2: 628-644, e164.

11. Saarto T., Wiffen P.J. Antidepressants for neuropathic pain. Cochrane Database Syst Rev 2007; 4: CD005454.

12. Kadiroglu A.K., Sit D., Kayabasi H. i wsp. The effect of venlafaxine $\mathrm{HCl}$ on painful peripheral diabetic neuropathy in patients with type 2 diabetes mellitus. $J$ Diabetes Complications 2008; 22: 241-245.

13. McIntyre R.S., Panjwani Z.D., Nguyen H.T. i wsp. The hepatic safety profile of duloxetine: a review. Expert Opin Drug Metab Toxicol 2008; 4: 281-285.

14. Goldstein D.J., Lu Y., Detke M.J. i wsp. Duloxetine vs. placebo in patients with painful diabetic neuropathy. Pain 2005; 116: 109-118.

15. Raskin J., Pritchett Y.L., Wang F. i wsp. A double-blind, randomized multicenter trial comparing duloxetine with placebo in the management of diabetic peripheral neuropathic pain. Pain Med 2005; 6: 346-356.

16. Wernicke J.F., Pritchett Y.L., D’Souza D.N. i wsp. A ran domized controlled trial of duloxetine in diabetic peripheral neuropathic pain. Neurology 2006; 67: 1411-1420.
17. Raskin P., Donofrio P.D., Rosenthal N.R. i wsp. Topiramate vs placebo in painful diabetic neuropathy: analgesic and metabolic effects. Neurology 2004; 63: 865-873.

18. Taylor C.P. Mechanisms of action of gabapentin. Drugs Today 1998; 34: 3-11.

19. Mellegers M.A., Furlan A.D., Milis A. Gabapentin for neuropathic pain: systemic review of controlled and uncontrolled literature. Clin J Pain 2001; 17: 284-295.

20. Moore R.A., Straube S., Wiffen P.J. i wsp. Pregabalin for acute and chronic pain in adults. Cochrane Database Syst Rev 2009; (3): CD007076.

21. Wiffen P.J., McQuay H.J., Rees J. i wsp. Gabapentin for acute and chronic pain. Cochrane Database Syst Rev 2005; (3): CD005452.

22. Hurley R.W., Maggie R.L., Adams M. i wsp. Pregabalin as a treatment for painful diabetic peripheral neuropathy: a metaanalysis. Reg Anesth Pain Med 2008; 33: 389-394.

23. Tassone D.M., Boyce E., Guyer J. i wsp. Pregabalin: a novel gamma-aminobutyric acid analogue in the treatment of neuropathic pain, partial-onset seizures, and anxiety disorders. Clin Therapeutics 2007; 29: 26-48.

24. Quilici S., Chancellor J., Lothgren M. i wsp. Meta-analysis of duloxetine vs pregabalin and gabapentin in the treatment of diabetic peripheral neuropathic pain. BMC Neurol 2009; 9: 6.

25. Morello C.M., Leekband S.G., Stoner C.P. i wsp. Randomized double-blind study comparing efficacy of gabapentin with amitiptyline on diabetic peripheral neuropathy pain. Arch Intern Med 1999; 159: 1931-1937.

26. Simpson D.A. Gabapentin and venlafaxine for treatment of painful diabetic neuropathy. J Clin Neuromuscul Dis 2001; 3: 53-62.

27. Sabatowski R., Galvez R., Cherry D.A. i wsp. Pregabalin reduces pain and improves sleep and mood disturbances in patients with post-herpetic neuralgia: results of a randomized, placebocontrolled clinical trial. Pain 2004; 109: 26-35.

28. Richter R.W., Portenoy R., Dharma U. i wsp. Relief of painful diabetic peripheral neuropathy with pregabalin: a randomized, placebo controlled trial. J Pain 2005; 6: 253-260.

29. Dworkin R.H., Corbin A.E., Young J.P. i wsp. Pregabalin for the treatment of postherpetic neuralgia. A randomized, placebocontrolled trial. Neurology 2003; 60: 1274-1283.

30. Gahimer J., Wernicke J., Yalcin I. i wsp. A retrospective pooled analysis of duloxetine safety in 23983 subjects. Curr Med Res Opin 2007; 23: 175-184.

31. Backonja M., Glanzman R.L. Gabapentin dosing for neuropathic pain: evidence from randomized, placebo controlled clinical trials. Clin Therapeutics 2003; 25: 81-104.

32. Freynhagen R., Strojek K., Griesing T. i wsp. Efficacy of pregabalin in neuropathic pain evaluated in a 12 -week, randomized, double-blind, multicentre, placebo-controlled trial of flexibleand fixed-dose regiments. Pain 2005; 115: 254-263.

33. Selak I. Pregabalin (Pfizer). Curr Opin Invest Drugs 2001; 2: 828-834.

34. Foley K.M. Opioids and chronic neuropathic pain. $N$ Engl J Med 2003; 348: 1279-1281.

35. Dellemijn P. Are opioids effective in relieving neuropathic pain? Pain 1999; 80: 453-462.

36. Gimbel J.S., Richards P., Portenoy R.K. Controlled-release oxycodone for pain in diabetic neuropathy: a randomised controlled trial. Neurology 2003; 60: 927-934. 